\title{
SEGURIDAD ALIMENTARIA Y SUS DESEQUILIBRIOS REGIONALES EN MÉXICO
}

\author{
Felipe Torres y Agustín Rojas ${ }^{\mathrm{a}}$
}

Fecha de recepción: 4 de noviembre de 2019. Fecha de aceptación: 20 de febrero de 2020.

$$
\text { http://doi.org/10.22201/iiec.20078951e.2020.201.69521 }
$$

Resumen. El presente trabajo busca analizar las dimensiones regionales de la seguridad alimentaria y sus desequilibrios territoriales en México. Mediante la aplicación del método de componentes principales, se elaboró un índice a nivel municipal y regional que, además de combinar información de variables diversas que se concentran en una medida única, sintetiza numéricamente tres de las cuatro dimensiones con que se mide la problemática: acceso, disponibilidad y utilización biológica. A la par se empleó el método de estratificación Dalenius-Hodges para establecer rangos de seguridad alimentaria a distintas escalas regionales. Los resultados muestran que las desigualdades socioeconómicas y territoriales, provocadas por los modelos de desarrollo aplicados en el pasado, afectan la seguridad alimentaria de la población en sus espacios regionales.

Palabras clave: seguridad alimentaria; política agrícola; desigualdades territoriales; Índice de Seguridad Alimentaria Municipal y Regional; método de Análisis de Componentes Principales.

Clasificación JEL: Q12; Q17; Q18; R11.

\section{FoOd SECURITY AND REgIONAL IMbalanCES IN MEXICO}

\begin{abstract}
This paper seeks to analyze regional dimensions of food security as a development issue, and its geographic imbalances in Mexico. Through the application of principal component analysis, an index was developed at the municipal and regional level. In addition to combining information for different variables which are consolidated into a single measurement, this index numerically synthesizes three of the four dimensions with which the problem is measured: access, availability and biological utilization. Meanwhile, the Dalenius-Hodges stratification method was used to establish food security ranges at different regional scales. The results show that the socioeconomic and geographic inequalities caused by the development models historically applied in Mexico affect the population's internal food security throughout its regional areas.
\end{abstract}

Key Words: food security; agricultural policy; geographic inequalities; Municipal and Regional Food Security Index; principal component analysis.

\footnotetext{
${ }^{a}$ Universidad Nacional Autónoma de México (UNAM), Instituto de Investigaciones Económicas, México. Correos electrónicos: felipet@unam.mx y arojas2910@gmail.com, respectivamente.
} 


\section{INTRODUCCIÓN ${ }^{1}$}

El cambio del modelo de desarrollo económico sustentado en la protección del mercado interno y sustitución de importaciones a otro, regido por la apertura comercial, afectó la seguridad alimentaria de México. Desde los años ochenta del siglo xx, enfrentó la vulnerabilidad e inseguridad de suministros. No obstante, dadas las condiciones de heterogeneidad social y territorial, los diagnósticos son incompletos: las mediciones tradicionales emplean promedios nacionales y no consideran indicadores regionales que permitan ubicar el desempeño local como limitante al acceso de la población a una alimentación suficiente.

Los estudios sobre problemas alimentarios que involucren un conjunto amplio de indicadores como el Producto Interno Bruto (РIB) per cápita a nivel municipal y de regiones medias, los niveles de producción de granos básicos y carnes, la desnutrición infantil según la prevalencia de talla baja o el equipamiento en el hogar en esas escalas son casi inexistentes. De esta manera, el tratamiento de la seguridad alimentaria desde la dimensión regional, requiere el desarrollo de metodologías y la construcción de indicadores con representatividad espacial para conocer las magnitudes reales de sus afectaciones en un marco asimétrico de desarrollo económico.

Se busca entonces responder a la pregunta de por qué las inequidades del desarrollo económico se expresan en desigualdades para la seguridad alimentaria a escala territorial, dentro de entornos productivo agroalimentarios desequilibrados.

La hipótesis que aquí se sustenta es que la seguridad alimentaria interna presenta un proceso gradual de deterioro que obedece tanto a la producción deficitaria de alimentos básicos, como al bajo nivel de accesibilidad, resultado del deterioro del poder adquisitivo, la inequidad social y las asimetrías regionales del desarrollo económico; lo anterior reproduce la vulnerabilidad alimentaria hacia estratos de población y territorios más amplios en entornos rurales y urbanos.

Este trabajo se compone de seis apartados, incluyendo esta introducción. En el segundo, se muestra la actual vulnerabilidad alimentaria que experimen-

1 Los autores agradecen profundamente a Adolfo Sánchez Almanza por sus asesorías para el tratamiento de la información estadística y su generosidad al permitir usar sus datos sobre el Producto Interno Bruto Municipal, que son resultado de su proyecto de investigación "El Producto Interno Bruto de los municipios de México, 1970-2015. Estimaciones para el análisis territorial”, actualmente en prensa. 
ta el país, cuyo origen se explica por la inequidad y las asimetrías internas que generó el modelo de economía abierta; en el tercero, se plantea la dimensión conceptual de la seguridad alimentaria; en el cuarto, se describe la metodología empleada y el proceso de cálculo de los indicadores, con la construcción del índice de seguridad alimentaria, sus rangos y representación regional; en el quinto, se exponen los resultados en su descripción y dimensión analítica de la problemática, considerando la hipótesis propuesta; y, finalmente, en el sexto, se presentan las conclusiones.

\section{LA VULNERABILIDAD ALIMENTARIA DE MÉXICO COMO REFLEJO DEL DESARROLLO ECONÓMICO}

Se tiene registro que desde los ańos noventa hasta el 2018, el PIB mantuvo una tasa de crecimiento promedio anual de apenas $2.6 \%$; sin considerar que todavía se mantiene a la baja, lo anterior resulta insuficiente para fortalecer la economía y alcanzar un bienestar social de manera sostenida; tampoco ayuda a mantener una dinámica que compense la disminución de recursos monetarios por otra vía distinta al ajuste del gasto público (véase gráfica 1).

Gráfica 1. México: evolución del PIB total, 1970-2018 (millones de pesos de 2013 y crecimiento \%)

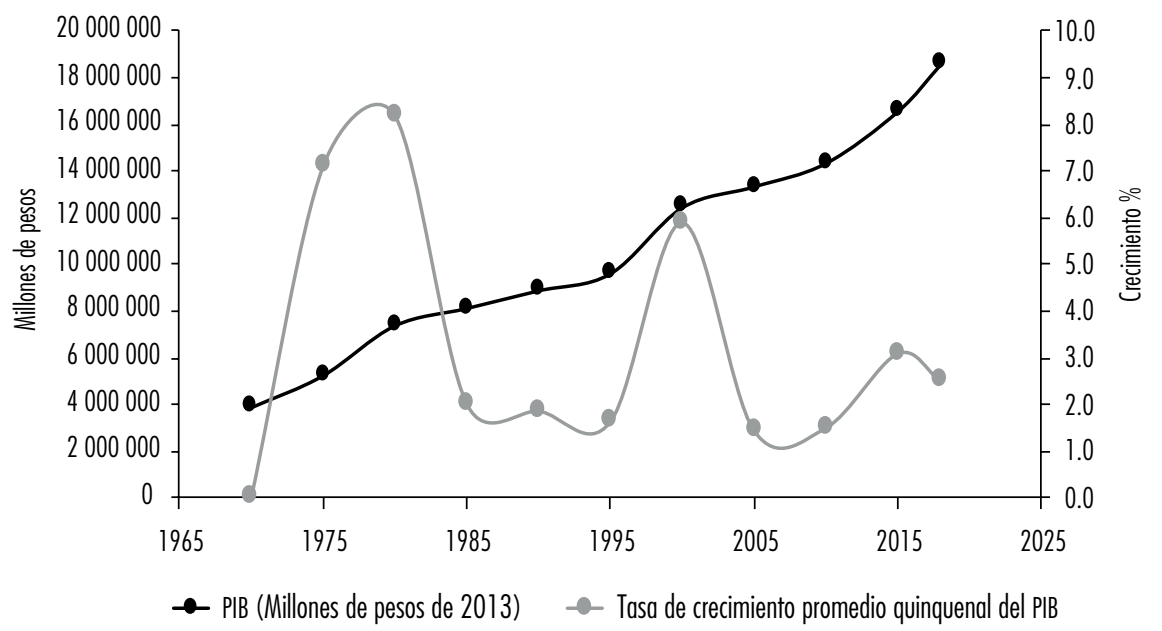

Nota: el valor de 2018 se estimó aplicando la tasa promedio anual de crecimiento del periodo 1990-2017.

Fuente: elaboración propia con base en Sánchez (2018) y Banco de Información Económica (BIE) del Instituto Nacional de Estadística y Geografía (INEGI). 
A 25 años de haberse implementado el TLCAN (ahora T-MEC) y a más de tres décadas del proceso de economía abierta, los resultados en materia alimentaria son poco favorables. Como saldos negativos se tienen la pérdida de la autosuficiencia alimentaria, así como el incremento de la dependencia externa en los productos de mayor consumo, que resultan más sensibles a los ciclos de alzas de precios (Puyana y Romero, 2009; Torres, 2017).

Durante en el periodo de 1993-2017, el arroz, maíz, frijol y trigo presentaron crecimientos negativos. El sorgo y la soya -insumos esenciales para la producción de carne, leche y huevo- mantienen una situación similar; a diferencia de frutas, hortalizas y otros productos denominados comerciales como el café o la caña de azúcar que registran crecimientos positivos, si bien no son básicos (Torres y Rojas, 2018).

La adquisición de alimentos en el exterior, coloca al país en una situación vulnerable, ya que el consumo interno está sujeto tanto a la crisis de producción interna como a las fluctuaciones de los precios internacionales. Esta problemática no ha podio corregirse en el ciclo de tendencia a la baja de los precios internacionales de productos básicos, debido a que están sujetos a las capacidades de crecimiento de la economía interna para ser adquiridos.

En el periodo 1993-2018, las exportaciones totales de alimentos reportaron una evolución favorable en su crecimiento, al pasar de US\$3955 a 34849 millones; sin embargo, tales cifras representan una situación artificial, ya que incorporaron productos como la cerveza y el tequila. Las importaciones totales de alimentos mostraron una tendencia creciente en el mismo periodo de análisis, al pasar de US\$5 713 a 28430 millones, lo que agravó la dependencia externa y pasó a ser un factor importante en los desequilibrios, tanto de la economía, como de la seguridad alimentaria interna (véase gráfica 2).

La dependencia alimentaria externa de México es más evidente en productos como carnes frescas o refrigeradas, semillas de soya, cebada y algodón o granos básicos como son el sorgo, trigo, maíz, frijol. Estos productos registran aumentos importantes en valor y volumen, pero su inercia se ha extendido hacia rubros como la carne de bovino, porcino y huevo; si bien mejora relativamente la situación en la leche fresca, en leche en polvo ocupa los primeros lugares en dependencia (Torres y Rojas, 2018).

Durante las últimas tres décadas, la importación de alimentos representa uno de los principales problemas para la seguridad alimentaria porque su crecimiento refleja la orientación negativa de las políticas de producción interna y el efecto de las oscilaciones de precios internacionales de alimentos. $\mathrm{El}$ incremento en las importaciones implica transferir demanda al exterior y constituye un freno para el crecimiento de la economía en su conjunto. 
Gráfica 2. México: evolución de las exportaciones e importaciones totales de alimentos, 1993-2018 (millones de dólares)

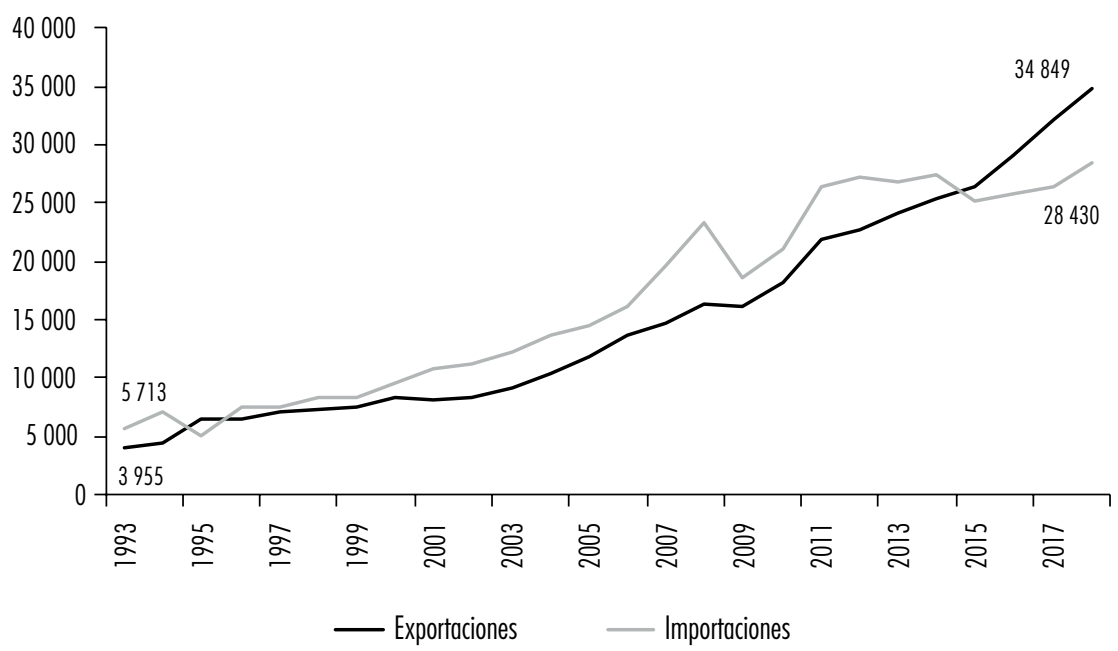

Fuente: elaboración propia con base en el BIE del INEGI.

El valor acumulado de las importaciones en los últimos 26 años supera los US\$433 988 millones: México importa US\$16 692 millones en promedio anual, lo que representa un impacto para el balance externo.

En 2017 el país dependía casi en un 40\% de las compras externas de alimentos y los granos básicos alcanzaron 30\% del consumo interno. Una situación similar ocurrió con la compra de carne de cerdo y de pollo que se incrementaron en un 16 y 11\%, respectivamente, e implicó que se destinaran más de US\$25 mil millones al pago de las importaciones alimentarias, inhibiendo con ello las condiciones de desarrollo del sector y de la economía en su conjunto (Torres y Rojas, 2018).

Para revertir la vulnerabilidad, México debe transformar su política económica mediante la diversificación de exportaciones que reduzcan la dependencia, sobre todo con Estados Unidos y fortalecer la producción interna de granos básicos. El Estado debe incrementar el crédito y mejorar los precios a los pequeños productores; aumentar la inversión en infraestructura agrícola, además de diseñar una política agrícola que asuma la seguridad alimentaria como una condición básica para la seguridad nacional. 


\section{LA SEGURIDAD ALIMENTARIA, UNA DIMENSIÓN CONCEPTUAL}

La vulnerabilidad alimentaria recrudecida con la aparición de nuevos fenómenos naturales asociados al cambio climático, la expansión de mercados de consumo como China o India, el control y la manipulación de los recursos fitogenéticos de acceso libre por agentes privados, la consolidación de los mercados de futuros y el control de precios, además de las disputas bélicas en países de Medio Oriente que llevan a éxodos masivos de las poblaciones hacia Europa y recién las caravanas de migrantes centroamericanos hacia Estados Unidos, implican retos conceptuales para ubicar las nuevas formas de manifestación de las asimetrías del desarrollo económico, sobre todo de las formas para resolver el problema a escala regional.

Entre otras razones, porque los diagnósticos de seguridad alimentaria se centran en promedios que no ubican en la misma magnitud a todos los hogares, aunque se ubiquen en el mismo rango de vulnerabilidad, ni a todos los territorios que han perdido capacidad para resolverla en su dimensión local.

De esta manera, el debate conceptual de la seguridad alimentaria trascendió el ámbito de organismos multilaterales y de foros mundiales en las décadas de los setenta y ochenta, para conformarse como elemento necesario en la formulación de estrategias por los gobiernos de todo el mundo. Lo anterior permitió la generación de diagnósticos con gran riqueza informativa.

El concepto más difundido por la Organización de las Naciones Unidas para la Alimentación y la Agricultura (FAO) sobre seguridad alimentaria se enfoca en el diagnóstico general de la problemática por países. Sin embargo, sus dimensiones de cobertura se mantienen como aspiración individual y sus recomendaciones no consideran los factores estructurales que inhiben el desempeño de las economías locales con sus limitaciones para lograrla; en general, sus estrategias son casuísticas o coyunturales.

De acuerdo con el organismo, la seguridad alimentaria se refiere al acceso de todas las personas a una alimentación inocua y nutritiva que les permita llevar en todo momento una vida sana. Se integra por cuatro dimensiones: acceso, disponibilidad, estabilidad del suministro y óptima utilización biológica (FAO, 2009); pero también por los alcances de la oferta, disponibilidad o estabilidad de alimentos adecuados, sin fluctuaciones o escasez estacional, ni restricciones de acceso a los alimentos inocuos y de calidad causados por la incapacidad financiera para adquirirlos (Rouzaud, 2008).

La crisis alimentaria mundial de 2008, evidenció una nueva perspectiva de análisis multifactorial donde la seguridad alimentaria no podía considerarse 
sólo como el resguardo de existencias para su especulación, sino como la necesidad de lograr la distribución y accesibilidad adecuada a los alimentos que integren las formas de previsión para contrarrestar el efecto de la volatilidad de los precios en la población vulnerable, además del fortalecimiento de las estructuras agrícolas locales integradas a políticas económicas permeadas por un principio de soberanía alimentaria en todas sus escalas (Torres, 2017).

La seguridad alimentaria debe integrar esa perspectiva multifactorialterritorial que sirva para generar diagnósticos integrales y responda a las particularidades territoriales, además de integrar una metodología que mida las magnitudes regionales como un problema estructural de la desigualdad originada en los desequilibrios que genera un tipo de desarrollo asimétrico, el cual afecta a grupos cada vez más amplios de población y de manera indiferenciada en zonas urbanas y regiones rurales.

\section{METODOLOGÍA PARA EL DIAGNÓSTICO DE LA SEGURIDAD ALIMENTARIA: UNA PERSPECTIVA ESTRUCTURAL DESDE LAS ASIMETRÍAS REGIONALES}

La mayoría de los diagnósticos sobre seguridad alimentaria identifican al déficit en la producción de alimentos o a las desigualdades en el acceso como causales de la vulnerabilidad. En los últimos 30 años, las estrategias gubernamentales aplicadas en México para el tratamiento del problema se enmarcan en la política social mediante programas focalizados que buscan atenuar los efectos adversos provocados por el modelo de desarrollo económico que afectan las condiciones alimentarias de la población y generan marginación y pobreza.

Aunque el sustento de los diagnósticos representan un avance para el conocimiento sobre la problemática de la seguridad alimentaria, al incorporar el criterio de medición de la pobreza por carencia de cobertura de la Canasta Básica Alimentaria (СвA), su espectro es limitado en términos conceptuales y metodológicos y resulta insuficiente para tratar la seguridad alimentaria con todas sus implicaciones. Sea por la limitación de indicadores o porque parten de promedios que esconden las particularidades de las zonas urbanas, regiones rurales y grupos sociales en sus patrones locales de consumo.

Esas limitaciones no explican la importancia que tienen para la vulnerabilidad alimentaria, el efecto de un tipo de desarrollo económico asimétrico que genera desigualdades e inhibe las capacidades de respuesta social y regional. Medir los alcances de la seguridad alimentaria, asumiendo que no afecta por igual a todos los individuos en su territorio, resulta necesario para el diagnóstico integral del problema. 
La mayoría de las propuestas metodológicas que sustentan los diagnósticos parten del concepto clásico de la FAO. Ejemplo de ello es la medición de la inseguridad alimentaria desarrollada por el organismo a principios de los años setenta del siglo pasado, donde conjugó indicadores referentes a la disponibilidad, accesibilidad y estabilidad alimentaria; si bien agrega de manera temporal y no sistemática algunos otros asociados con desastres naturales, desigualdad social, conflictos armados y, en años recientes calidad, desperdicio y problemas de salud como sobrepeso y obesidad (FAO, 2016 y 2018).

Recientemente han surgido otras propuestas de medición para el diagnóstico de la seguridad alimentaria, como el Índice Global de Seguridad Alimentaria Familiar (Morón y Schejtman, 1997), o el Índice Global de Seguridad Alimentaria desarrollado por la Unidad de Inteligencia (UIE y DuPont, 2017), que incluyen también indicadores para entender las magnitudes de la seguridad alimentaria a partir de la prevalencia de factores de obesidad y desperdicio de alimentos, si bien en escalas agregadas para el cálculo que no dan cuenta de las condiciones que prevalecen en escalas territoriales más pequeñas.

Más allá de las escalas agregadas, surge la necesidad de desarrollar una metodología que permita la construcción de un indicador de mayor representatividad espacial y que refleje tal vulnerabilidad, tomando en cuenta la compleja recurrencia de factores de medición, la dificultad de incorporar su desagregación, su dispersión-agrupación espacial en un mismo territorio o la evolución del concepto asociado a la complejidad social.

La propuesta aquí vertida sobre medición y diagnóstico parte de la elaboración de un Índice de Seguridad Alimentaria Municipal y Regional, empleando el método de Análisis de Componentes Principales (ACP), que permite combinar información de diversas variables en una medida única que sintetiza numéricamente tres de las cuatro dimensiones asociadas a la seguridad alimentaria: acceso, disponibilidad y utilización biológica. El resultado implica la elaboración de mapas de vulnerabilidad para todo el territorio mexicano a través del método de estratificación Dalenius-Hodges, y que pueden servir también para la planeación y evaluación de la política alimentaria.

Las escalas de análisis para la presente investigación son la municipal y regional. Esta última parte del nivel de región media que han utilizado los Planes Estatales de Desarrollo para fines de planeación en las diferentes actividades de los estados de México y agrupan al total de municipios en las 214 regiones consideradas. Su utilidad radica en identificar zonas rurales y urbanas de alta y baja especialización y niveles de producción, diferenciar espacios con problemáticas comunes y heterogéneas y, además, conocer la magnitud de los desequilibrios internos provocados por las asimetrías del desarrollo 
económico; en síntesis, diagnostica la situación que guarda la seguridad alimentaria desde una dimensión regional.

Para la construcción del Índice de Seguridad Alimentaria Municipal y Regional se seleccionaron indicadores que miden la situación regional de la seguridad alimentaria, más allá de escalas nacionales o estatales, ya que debe abordarse según los distintos niveles de desarrollo humano en su escala territorial y en el contexto de su desarrollo económico, atendiendo a tres de las cuatro dimensiones propuestas por la FAO ya referidas.

Debido a que el análisis de la seguridad alimentaria debe ubicarse también en una perspectiva multifactorial-territorial, donde confluyen múltiples factores internos y externos que la vulneran y provocan disparidades en el territorio, no es posible medirla con una sola variable, menos cuando se analiza espacialmente. Esta consideración llevó a la selección de 13 indicadores, de los que se tiene información desagregada por municipio en los cinco cortes transversales temporales (2000, 2005, 2010, 2015 y 2018). Ello permite analizar los cambios en la situación de la seguridad alimentaria a través del comportamiento del índice en el tiempo. Además de la disponibilidad de información en la escala requerida; otro criterio de selección radicó en que dicho periodo se sitúa en el vértice de la apertura comercial y la consolidación del modelo de desarrollo actual donde la seguridad alimentaria presenta una dinámica distinta en comparación con décadas previas.

A continuación se presenta la forma de cálculo de los indicadores empleados en la construcción del índice. Cabe señalar que si bien la clasificación responde a la propuesta de la FAO en esas tres de sus cuatro dimensiones, implica sobre todo sus posibilidades de análisis regional (véanse cuadros 1, 2 y 3 ).

Una vez calculados los indicadores, se recurrió al ACP para la construcción del Índice de Seguridad Alimentaria Municipal y Regional, técnica de estadística multivariante que permite obtener una unidad de medida sintética para evaluar el impacto global de un conjunto de variables, conservando al máximo la información que cada una de ellas aporta al conjunto (Hair et al., 2014). Para ello, se consideró el total de municipios de México para cada corte transversal temporal: 2443 en el 2000; 2454 en 2005; 2456 en 2010; 2457 en 2015; y 2458 en 2018. En el caso regional, para todos los años, se mantuvo la clasificación de 214 regiones medias, haciendo consistente el análisis en términos, independiente a la incorporación de nuevos municipios.

Para obtener el índice, se construyó una base de datos que incluye la información de los indicadores seleccionados donde se aplicó el ACP. Acorde con la metodología, el primer paso consistió en estandarizar los indicadores a fin de hacerlos comparables, es decir, homogeneizar las disparidades de longi- 
tud, promedio y desviación. En el arreglo matricial, cada municipio o región media, dependiendo de la escala, representa un caso observado y ocupa un renglón; por otra parte, en las columnas de cada renglón aparecen los valores de los 13 indicadores seleccionados.

Cuadro 1. Indicadores de acceso económico a los alimentos

\begin{tabular}{|c|c|c|c|c|}
\hline Nombre & Definición operacional & $\begin{array}{l}\text { Unidad } \\
\text { de medida }\end{array}$ & $\begin{array}{l}\text { Nivel de } \\
\text { aplicación }\end{array}$ & $\begin{array}{l}\text { Fuentes de } \\
\text { información }\end{array}$ \\
\hline \multirow[t]{2}{*}{$\begin{array}{l}\text { Producto Interno Bruto } \\
\text { per cápita }\end{array}$} & [PIB municipal ${ }^{(a)} /$ Población municipal] & $\begin{array}{l}\text { Millones de pesos } \\
\text { constantes de } 2008\end{array}$ & Municipal & $\begin{array}{l}\text { Sánchez } \\
\text { (2018) }\end{array}$ \\
\hline & $\begin{array}{l}\text { [PIB por Región Media/Población por } \\
\text { Región Media] }\end{array}$ & $\begin{array}{l}\text { Millones de pesos } \\
\text { constantes de } 2008\end{array}$ & $\begin{array}{l}\text { Región } \\
\text { Media }\end{array}$ & \\
\hline \multirow[t]{2}{*}{$\begin{array}{l}\text { Porcentaje de población } \\
\text { en situación de pobreza } \\
\text { alimentaria }\end{array}$} & $\begin{array}{l}\text { [Personas en pobreza alimentaria }^{(b)} \\
\text { por municipio/Población total por } \\
\text { municipio }{ }^{\star} 100\end{array}$ & Porcentaje & Municipal & $\begin{array}{l}\text { CONEVAL } \\
(2017)\end{array}$ \\
\hline & $\begin{array}{l}\text { [Personas en pobreza alimentaria por } \\
\text { Región Media / Población total por } \\
\text { Región Media] }{ }^{\star} 100\end{array}$ & Porcentaje & $\begin{array}{l}\text { Región } \\
\text { Media }\end{array}$ & $\begin{array}{l}\text { INEGI } \\
(2015)\end{array}$ \\
\hline
\end{tabular}

Notas: ${ }^{(a)}$ Los cálculos provienen de Sánchez (2018); ${ }^{(b)}$ las cifras de 2000, 2005 y 2010 se tomaron de la variable pobreza alimentaria de la metodología de la pobreza por ingreso. La cifra para 2015 corresponde a la variable de "Población con ingreso inferior a la línea de bienestar mínimo" de la metodología de pobreza multidimensional.

Fuente: elaboración propia.

Cuadro 2. Indicadores de disponibilidad de alimentos

\begin{tabular}{|c|c|c|c|c|}
\hline Nombre & Definición operacional & $\begin{array}{l}\text { Unidad de } \\
\text { medida }\end{array}$ & $\begin{array}{l}\text { Nivel de } \\
\text { aplicación }\end{array}$ & Fuentes de información \\
\hline \multirow{2}{*}{$\begin{array}{l}\text { Porcentaje de } \\
\text { suficiencia de } \\
\text { granos básicos: } \\
\text { arroz, frijol, } \\
\text { maíz, trigo }\end{array}$} & $\begin{array}{l}\text { [Disponibilidad Municipal (producción/ } \\
\text { población)/Consumo Municipal } \\
\text { (consumo per cápita }{ }^{\star} \text { población)]*100 }\end{array}$ & Porcentaje & Municipal & $\begin{array}{l}\text { Sistema de Información Agroalimentaria } \\
\text { y Pesquera de la Secretaría de } \\
\text { Agricultura y Desarrollo Rural (SAGARPA) }\end{array}$ \\
\hline & $\begin{array}{l}\text { [Disponibilidad por Región Media } \\
\text { (producción/población) / Consumo } \\
\text { por Región Media (consumo per } \\
\text { cápita*población)] } 100\end{array}$ & Porcentaje & $\begin{array}{l}\text { Región } \\
\text { Media }\end{array}$ & INEGI $(2000,2005,2010 a, 2015)$ \\
\hline $\begin{array}{l}\text { Porcentaje de } \\
\text { suficiencia de } \\
\text { carnes: bovino, } \\
\text { porcino, ave }\end{array}$ & $\begin{array}{l}\text { [Disponibilidad Municipal (producción/ } \\
\text { población)/Consumo Municipal } \\
\text { (consumo per cápita }{ }^{\star} \text { población)]*100 }\end{array}$ & Porcentaje & Municipal & SAGARPA \\
\hline
\end{tabular}




\begin{tabular}{lllll}
\hline Nombre & Definición operacional & $\begin{array}{l}\text { Unidad de } \\
\text { medida }\end{array}$ & $\begin{array}{l}\text { Nivel de } \\
\text { aplicación }\end{array}$ & Fuentes de información \\
\hline & [Disponibilidad por Región Media & Porcentaje & Región & INEG $(2000,2005,2010 a, 2015)$ \\
(producción/población)/Consumo & & Media & \\
por Región Media (consumo per & & & \\
cápita*población) $]^{*} 100$ & & & \\
\hline
\end{tabular}

Fuente: elaboración propia.

Cuadro 3. Indicadores de utilización biológica de los alimentos

\begin{tabular}{|c|c|c|c|c|}
\hline Nombre & Definición operacional & $\begin{array}{l}\text { Unidad de } \\
\text { medida }\end{array}$ & $\begin{array}{l}\text { Nivel de } \\
\text { aplicación }\end{array}$ & Fuentes de información \\
\hline \multirow{2}{*}{$\begin{array}{l}\text { Porcentaje de preva- } \\
\text { lencia de talla baja } \\
\text { en niños de primer } \\
\text { año de primaria }\end{array}$} & Talla baja $<2 \sigma$ & Porcentaje $^{0}$ & Municipal & $\begin{array}{l}\text { DIF-SEP-INCMNSZ (1994, 1997, } \\
\text { 2004); DIF-SEP-SSA-INCMNSZ } \\
\text { (2006); Ávila et al.(2016) }\end{array}$ \\
\hline & Talla baja $<2 \sigma$ & Porcentaje & $\begin{array}{l}\text { Región } \\
\text { Media }\end{array}$ & $\begin{array}{l}\text { INEGI }(2000,2005,2010 a, \\
2015)\end{array}$ \\
\hline \multirow[t]{2}{*}{$\begin{array}{l}\text { Porcentaje de pobla- } \\
\text { ción de } 15 \text { años } \\
\text { y más analfabeta }\end{array}$} & $\begin{array}{l}\text { [Población de } 15 \text { años y más analfabeta por } \\
\text { Municipio/Población total de } 15 \text { años por } \\
\text { Municipio] }{ }^{\star} 100\end{array}$ & Porcentaje & Municipal & $\begin{array}{l}\text { INEGI }(2000,2005,2010 a \text {, } \\
\text { 2015) }\end{array}$ \\
\hline & $\begin{array}{l}\text { [Población de } 15 \text { años y más analfabeta por } \\
\text { Región Media/Población total de } 15 \text { años } \\
\text { por Región Media] }{ }^{\star} 100\end{array}$ & Porcentaje & $\begin{array}{l}\text { Región } \\
\text { Media }\end{array}$ & $\begin{array}{l}\text { INEGI }(2000,2005,2010 a, \\
2015)\end{array}$ \\
\hline \multirow{2}{*}{$\begin{array}{l}\text { Porcentaje de } \\
\text { población derecho- } \\
\text { habiente a servicios } \\
\text { de salud en el IMSS }\end{array}$} & $\begin{array}{l}\text { [Población derechohabiente al IMSS por } \\
\text { Municipio/Población total por Municipio] }{ }^{\star} 100\end{array}$ & Porcentaje & Municipal & $\begin{array}{l}\text { INEGI }(2000,2005,2010 a, \\
2015)\end{array}$ \\
\hline & $\begin{array}{l}\text { [Población derechohabiente al IMSS por Región } \\
\text { Media/Población total por Región Media] }{ }^{\star} 100\end{array}$ & Porcentaje & $\begin{array}{l}\text { Región } \\
\text { Media }\end{array}$ & $\begin{array}{l}\text { INEGI }(2000,2005,2010 a, \\
2015)\end{array}$ \\
\hline $\begin{array}{l}\text { Porcentaje de } \\
\text { viviendas con piso } \\
\text { de tierra }\end{array}$ & $\begin{array}{l}\text { [Viviendas con piso de tierra por Municipio/ } \\
\text { Total de viviendas particulares habitadas por } \\
\text { Municipio }{ }^{\star} 100\end{array}$ & Porcentaje & Municipal & $\begin{array}{l}\text { INEGI }(2000,2005,2010 a, \\
2015)\end{array}$ \\
\hline $\begin{array}{l}\text { Porcentaje de } \\
\text { viviendas con piso } \\
\text { de tierra }\end{array}$ & $\begin{array}{l}\text { [Viviendas con piso de tierra por Región Media/ } \\
\text { Total de viviendas particulares habitadas por } \\
\text { Región Media] }{ }^{*} 100\end{array}$ & Porcentaje & $\begin{array}{l}\text { Región } \\
\text { Media }\end{array}$ & $\begin{array}{l}\text { INEGI }(2000,2005,2010 a, \\
2015)\end{array}$ \\
\hline \multirow[t]{2}{*}{$\begin{array}{l}\text { Porcentaje de } \\
\text { viviendas que no } \\
\text { disponen de drenaje }\end{array}$} & $\begin{array}{l}\text { [Viviendas que no disponen de drenaje por } \\
\text { Municipio/Total de viviendas particulares } \\
\text { habitadas por Municipio }{ }^{\star} 100\end{array}$ & Porcentaje & Municipal & $\begin{array}{l}\text { INEGI }(2000,2005,2010 a, \\
2015)\end{array}$ \\
\hline & $\begin{array}{l}\text { [Viviendas que no disponen de drenaje por } \\
\text { Región Media/Total de viviendas particulares } \\
\text { habitadas por Región Media] }{ }^{\star} 100\end{array}$ & Porcentaje & $\begin{array}{l}\text { Región } \\
\text { Media }\end{array}$ & $\begin{array}{l}\text { INEGI }(2000,2005,2010 a, \\
2015)\end{array}$ \\
\hline
\end{tabular}


Cuadro 3. Indicadores de utilización biológica de los alimentos (continuación)

\begin{tabular}{|c|c|c|c|c|}
\hline Nombre & Definición operacional & $\begin{array}{l}\text { Unidad de } \\
\text { medida }\end{array}$ & $\begin{array}{l}\text { Nivel de } \\
\text { aplicación }\end{array}$ & Fuentes de información \\
\hline \multirow{2}{*}{$\begin{array}{l}\text { Porcentaje de } \\
\text { viviendas que no } \\
\text { disponen de excusa- } \\
\text { do } 0 \text { sanitario }\end{array}$} & $\begin{array}{l}\text { [Viviendas particulares habitadas sin excusado } \\
0 \text { sanitario por Municipio/Total de viviendas } \\
\text { particulares habitadas por Municipio] }{ }^{\star} 100\end{array}$ & Porcentaje & Municipal & $\begin{array}{l}\text { INEGI }(2000,2005,2010 a \text {, } \\
2015)\end{array}$ \\
\hline & $\begin{array}{l}\text { [Viviendas particulares habitadas sin excusado } \\
0 \text { sanitario por Región Media/Total de viviendas } \\
\text { particulares habitadas por Región Media] }{ }^{\star} 100\end{array}$ & Porcentaje & $\begin{array}{l}\text { Región } \\
\text { Media }\end{array}$ & $\begin{array}{l}\text { INEGI }(2000,2005,2010 a \text {, } \\
2015)\end{array}$ \\
\hline \multirow{2}{*}{$\begin{array}{l}\text { Porcentaje de } \\
\text { viviendas que no } \\
\text { disponen de agua } \\
\text { entubada de la red } \\
\text { pública }\end{array}$} & $\begin{array}{l}\text { [Viviendas sin agua entubada por Municipio/ } \\
\text { Total de viviendas particulares habitadas por } \\
\text { Municipio }{ }^{\star} 100\end{array}$ & Porcentaje & Municipal & $\begin{array}{l}\text { INEGI }(2000,2005,2010 a \text {, } \\
2015)\end{array}$ \\
\hline & $\begin{array}{l}\text { [Viviendas sin agua entubada por Región } \\
\text { Media/Total de viviendas particulares habitadas } \\
\text { por Región Media] }{ }^{\star} 100\end{array}$ & Porcentaje & $\begin{array}{l}\text { Región } \\
\text { Media }\end{array}$ & $\begin{array}{l}\text { INEGI }(2000,2005,2010 a \text {, } \\
2015)\end{array}$ \\
\hline \multirow[t]{2}{*}{$\begin{array}{l}\text { Porcentaje de } \\
\text { viviendas que } \\
\text { no disponen de } \\
\text { electricidad }\end{array}$} & $\begin{array}{l}\text { [Viviendas sin electricidad por Municipio/ } \\
\text { Total de viviendas particulares habitadas por } \\
\text { Municipio }{ }^{\star} 100\end{array}$ & Porcentaje & Municipal & $\begin{array}{l}\text { INEGI }(2000,2005,2010 a \text {, } \\
2015)\end{array}$ \\
\hline & $\begin{array}{l}\text { [Viviendas sin electricidad por Región Media/ } \\
\text { Total de viviendas particulares habitadas por } \\
\text { Región Media] }{ }^{*} 100\end{array}$ & Porcentaje & $\begin{array}{l}\text { Región } \\
\text { Media }\end{array}$ & $\begin{array}{l}\text { INEGI }(2000,2005,2010 a \text {, } \\
2015)\end{array}$ \\
\hline \multirow[t]{2}{*}{$\begin{array}{l}\text { Porcentaje de } \\
\text { viviendas que } \\
\text { no disponen de } \\
\text { refrigerador }\end{array}$} & $\begin{array}{l}\text { [Viviendas sin refrigerador por Municipio/ } \\
\text { Total de viviendas particulares habitadas por } \\
\text { Municipio }{ }^{\star} 100\end{array}$ & Porcentaje & Municipal & $\begin{array}{l}\text { INEGI }(2000,2005,2010 a \text {, } \\
2015)\end{array}$ \\
\hline & $\begin{array}{l}\text { [Viviendas sin refrigerador por Región Media/ } \\
\text { Total de viviendas particulares habitadas por } \\
\text { Región Media] }{ }^{\star} 100\end{array}$ & Porcentaje & $\begin{array}{l}\text { Región } \\
\text { Media }\end{array}$ & $\begin{array}{l}\text { INEGI }(2000,2005,2010 a \text {, } \\
2015)\end{array}$ \\
\hline
\end{tabular}

Notas: ${ }^{a)}$ Las cifras de Prevalencia de talla baja por municipio se presentan en porcentaje. Para el caso de Región Media, se obtiene el valor promedio del conjunto de municipios que la integran (se presentan en porcentaje); ${ }^{b}$ debido a que los puntos de interés son los años 2000, 2005, 2010 y 2015, se realizó una interpolación lineal con los datos de Prevalencia de talla baja en niños de primer grado de primaria en cada uno de los municipios a partir de los datos reportados en 1994, 1999, 2004 y 2016. Se utilizan dos pendientes para estas interpolaciones: 1) una pendiente constante entre 1999 y 2004; y 2) una pendiente constante entre 2004 y 2016.

Fuente: elaboración propia. 
Para el Índice de Seguridad Alimentaria por Región Media, ${ }^{2}$ la estandarización se efectuó mediante la fórmula $Z_{i, j}=\frac{I_{i, j}-\overline{I_{j}}}{d s_{j}}$, donde:

$Z_{i, j}$ : es el indicador $j$ estandarizado de la región media $i$,

$I_{i, j}$ : es el indicador socioeconómico $j$ de la región media $i$,

$\overline{I_{j}}$ : es el promedio aritmético de los valores del indicador $j, \mathrm{y}$

$d s_{j}$ : es la desviación estándar insesgada del indicador $j$.

Como resultado, se obtuvo la matriz estandarizada de indicadores:

$$
z=\left[\begin{array}{cccc}
z_{1,1} & z_{1,2} & \cdots & z_{1,13} \\
z_{2,1} & z_{2,2} & \cdots & z_{2,13} \\
\vdots & \vdots & \vdots & \vdots \\
z_{n, 1} & z_{n, 2} & \cdots & z_{n, 13}
\end{array}\right]
$$

Posteriormente, a partir de $Z$, se construyó la matriz de correlaciones, la cual muestra la relación existente entre los indicadores y las nuevas variables; sus valores oscilan entre 0 y 1 :

$$
\operatorname{Corr}=\left[\begin{array}{cccc}
1_{1,1} & q_{1,2} & \cdots & q_{13,1} \\
q_{1,2} & 1_{2,2} & \cdots & q_{13,2} \\
\vdots & \vdots & \vdots & \vdots \\
q_{13,1} & q_{13,2} & \cdots & 1_{13,13}
\end{array}\right]
$$

De esta matriz, se obtuvieron los valores propios $\omega_{1, k}$ para cada uno (las letras minúsculas $w$ expresan un vector $k$ con peso para cada indicador). Después se estableció su orden jerárquico:

$$
\lambda_{1} \geq \lambda_{2} \geq \lambda_{3} \geq \lambda_{4} \geq \lambda_{5} \geq \lambda_{6} \geq \lambda_{7} \geq \lambda_{8} \geq \lambda_{9} \geq \lambda_{10} \geq \lambda_{10} \geq \lambda_{12} \geq \lambda_{13}>0
$$

A partir de los valores propios, se consiguieron los vectores propios (o componentes):

2 Este procedimiento se replicó para la construcción del Índice de Seguridad Alimentaria Municipal. 


$$
\begin{gathered}
y_{1}=\omega_{1,1} z_{1}+\omega_{1,2} z_{2}+\cdots+\omega_{1,13} z_{13} \\
y_{2}=\omega_{2,1} z_{1}+\omega_{2,2} z_{2}+\cdots+\omega_{2,13} z_{13} \\
\vdots \\
y_{13}=\omega_{13,1} z_{1}+z_{13,2} z_{2}+\cdots+\omega_{13,13} z_{13}
\end{gathered}
$$

En función de lo anterior, se pondera la importancia de cada componente por la proporción que representa del total, es decir, por la varianza explicada. Finalmente, para la construcción del índice, el primer vector propio se multiplica por la matriz $\underline{\omega}_{1 *}^{\prime} \underline{z}$.

Al índice elaborado mediante ACP, se aplicó el método de estratificación Dalenius-Hodges para determinar los rangos de seguridad alimentaria por municipio y región media, los cuales se categorizaron en: seguridad alimentaria, inseguridad alimentaria leve, inseguridad alimentaria moderada e inseguridad alimentaria severa. De acuerdo con la metodología (INEGI, 2010b), para la conformación de estratos, sean $\mathrm{N}$ el número de observaciones y L el número de estratos se ordenaron las observaciones de manera ascendente, para agruparlas después en $\mathrm{J}$ clases, donde $\mathrm{J}=\min \left(\mathrm{L}^{*} 10, \mathrm{n}\right)$. Una vez obtenidas las clases, se calcularon los límites para cada una de la siguiente manera:

$$
\begin{aligned}
\lim \inf C k & =\min \{X(i)\}+(k-1) * \frac{\max \{X(i)\}-\min \{X(i)\}}{J} \\
\lim \sup C k & =\min \{X(i)\}+(k) * \frac{\max \{X(i)\}-\min \{X(i)\}}{J}
\end{aligned}
$$

A partir de dichos límites, se obtuvo la frecuencia de casos en cada clase $f i(i=1, \cdots, J)$; después, se calculó la raíz cuadrada de la frecuencia de cada clase y luego se acumuló la suma de la raíz cuadrada de las frecuencias, es decir:

$$
C i=\sum_{h=1}^{i} \sqrt{f h(i=1, \cdots, J)}
$$

Se dividió el último valor acumulado entre el número de estratos $Q=\frac{1}{L} C j$. Los puntos de corte de cada estrato se tomaron sobre el acumulado de la raíz cuadrada de las frecuencias en cada clase de acuerdo a lo siguiente $Q, 2 Q, \cdots,(h-1) Q$. El criterio consistió en que si el valor $Q$ quedaba entre dos clases se tomaba como punto de corte de la clase que presente la misma distancia a $Q$. Finalmente, los límites de los $h$-estratos conformados serían los correspondientes a los límites inferior y superior de las clases comprendidas en cada estrato. 
Los resultados obtenidos de la aplicación del método de ACP y de la estratificación de Dalenius-Hodges a los valores del Índice de Seguridad Alimentaria Municipal y de Región Media se presentan a continuación.

\section{DIMENSIONES DE LA SEGURIDAD ALIMENTARIA EN MÉXICO: UN ENFOQUE REGIONAL}

Los resultados obtenidos muestran las desigualdades socioeconómicas y territoriales que el modelo de desarrollo de economía abierta generó en México, sobre todo los efectos adversos que ha tenido en la situación alimentaria de sus habitantes. Del total de municipios delimitados administrativamente al inicio del periodo referido, sólo $25.2 \%$ de ellos alcanzaron el rango de seguridad alimentaria y $18.7 \%$ se ubicaron en inseguridad alimentaria severa, $29.5 \%$ en inseguridad alimentaria leve y $26.6 \%$ en inseguridad alimentaria moderada. Si bien sumados los rangos de leve y moderada alcanzaban poco más del $50 \%$ de los municipios en situación crítica, la diferencia entre seguridad alimentaria e inseguridad alimentaria leve (incluso el rango de moderada y severa) fue menos pronunciada con respecto a 2018, lo cual supondría el registro de mejores condiciones alimentarias a nivel de los municipios del país por efecto de la reconcentración de municipios en zonas metropolitanas. Asimismo, las peores condiciones correspondieron también a los municipios localizados en las nueve entidades federativas con los más altos grados de marginación (véase cuadro 4).

Sin embargo, esta condición de rezago debido a problemas estructurales dentro del modelo de desarrollo económico se profundizó en 2018: el número de municipios en seguridad alimentaria disminuyó a 460, lo que representa una pérdida de 155 municipios en esta condición respecto al 2000; sin embargo, el número aumentó a 704 en inseguridad alimentaria severa, por lo que las condiciones críticas de la seguridad alimentaria se incrementaron incluso de manera proporcional.

De acuerdo a los resultados, la población en situación de seguridad alimentaria localizada en los municipios se incrementó en más de 9 millones de personas en términos absolutos, esto obedece de nueva cuenta a los típicos desequilibrios territoriales que el modelo de desarrollo económico ha generado y no a una mejoría, como ya se ha indicado, entre la población desplazada de este rango (véase cuadro 5).

Se muestra que $70 \%$ de la población nacional se localiza en zonas urbanas y más del $60 \%$ en zonas metropolitanas que, además de conservar su rango 


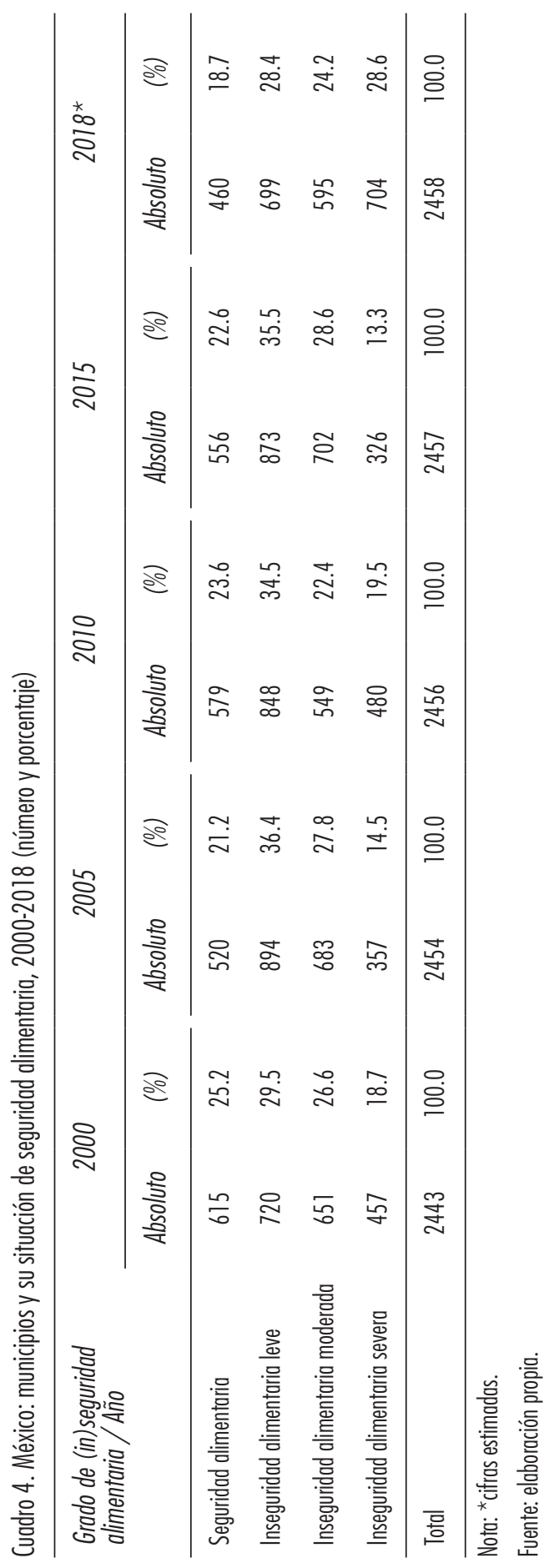




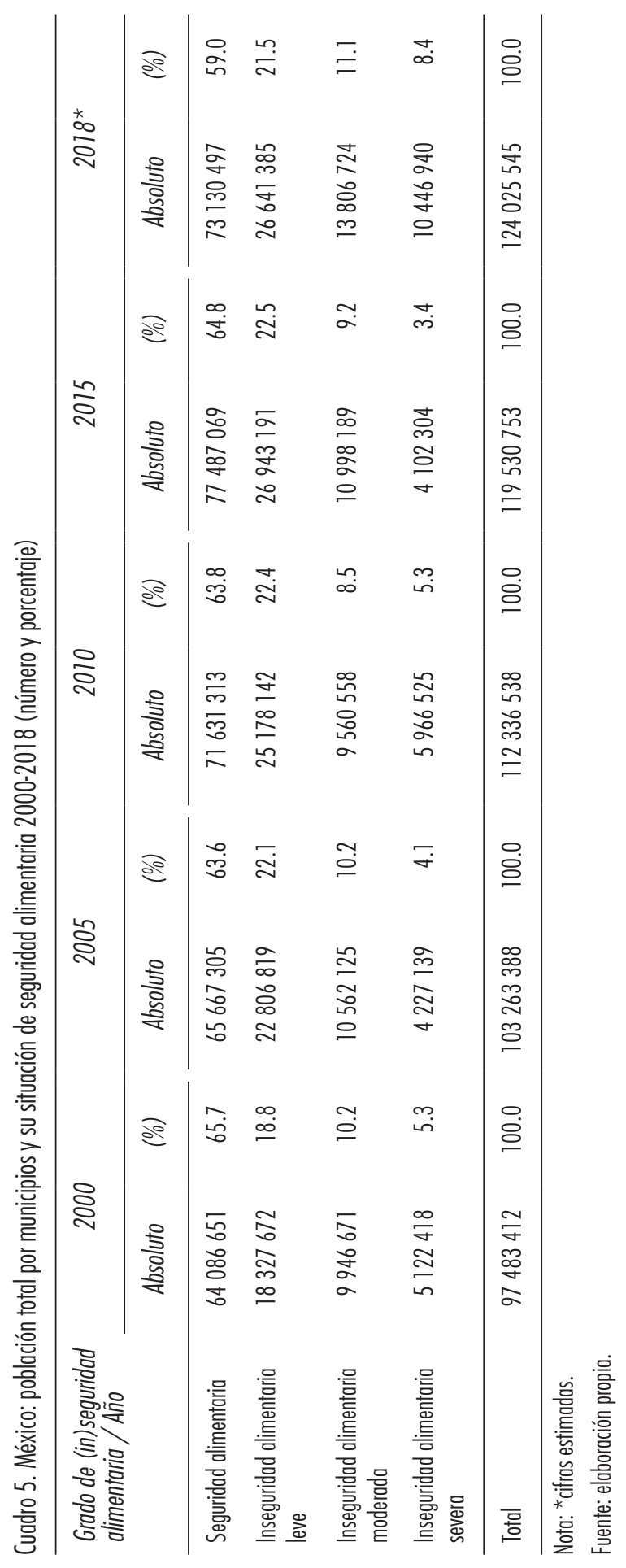


de municipio, se expanden mediante el proceso de conurbación hacia otro gran número de municipios. Como la alimentación en las ciudades resulta por lo regular de mayor calidad y diversificación, independiente de su heterogeneidad en los niveles sociales, ayuda al alza en los promedios generales, pero esconde la situación real a medida que la población pobre que cambió de ubicación territorial mantiene en lo general los mismos niveles de inseguridad. De este rezago estructural en la relación población-municipio en inseguridad alimentaria severa, se infiere que la marginación y los niveles de vulnerabilidad alimentaria están aún muy lejos de superarse.

En igual sentido, estos resultados municipales no varían significativamente respecto a la escala regional. Si bien en el 2000, es decir, al inicio del periodo analizado, se registraron 59 regiones medias con una cobertura adecuada de su seguridad alimentaria y observaron un relativo incremento en número a 63 que se mantuvo en 2005 y 2010, disminuyó hasta 43 en 2015 como resultado de la crisis económica y alimentaria, para 2018 alcanzó 55. En dirección contraria, pero complementaria con la explicación anterior, las 64 regiones medias que al inicio del periodo observaron inseguridad alimentaria leve, mismas que habían disminuido a 61 en 2005, comenzaron a manifestar con 66 un claro repunte en 2010 que se disparó hasta 84 en 2015, y que volvió a bajar a 78 en 2018, lo que es preocupante, ya que la frontera de rango se encuentra cercana a la inseguridad alimentaria severa. Una situación parecida, aunque menos intensa, ocurrió con las ubicadas en inseguridad alimentaria moderada que se redujeron de 54 en el 2000 a 44 al final del periodo (véase cuadro 6).

En el caso de las regiones medias ubicadas en el rango de inseguridad alimentaria severa, que es donde se concentra la población más marginada y en un espacio cercano a los niveles de hambre o pobreza extrema según otras mediciones, se registra que, de las 37 que se registraron en el 2000, aumentaron a 57 en 2018, lo que expresa el deterioro en las condiciones de reproducción de la sociedad (véase mapa 1).

En primer lugar, las dinámicas de movilidad de la población rural, sobre todo hacia Estados Unidos, que también se reconcentraron en centros urbanos del país, permitieron que la población en condición de inseguridad alimentaria severa no fuera contabilizada en esas regiones sino en otras. Asimismo, el mejoramiento del envío de remesas que se destinan en casi $80 \%$ al consumo, donde la mayor parte se ocupa para comprar alimentos, ayudaron a una mejor estabilidad y nivel de consumo entre familias y comunidades pobres, aunque el monto varíe, no revirtieron esa tendencia estructural al deterioro constante. 


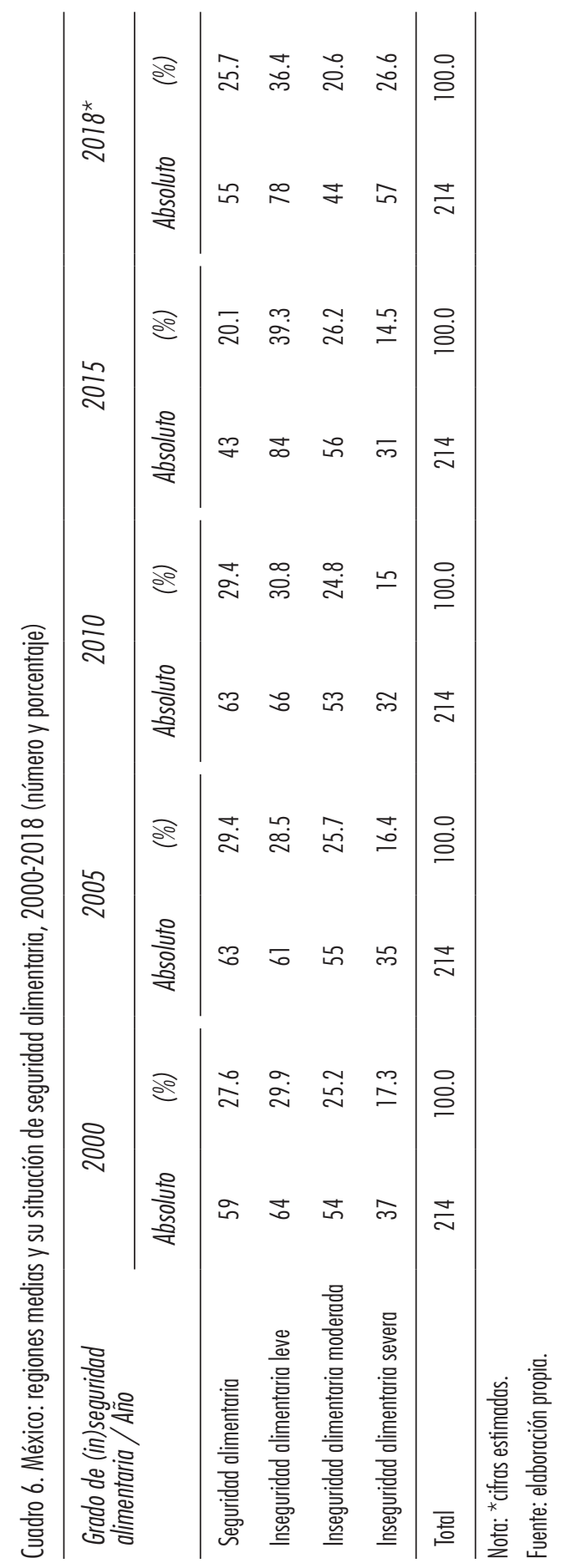




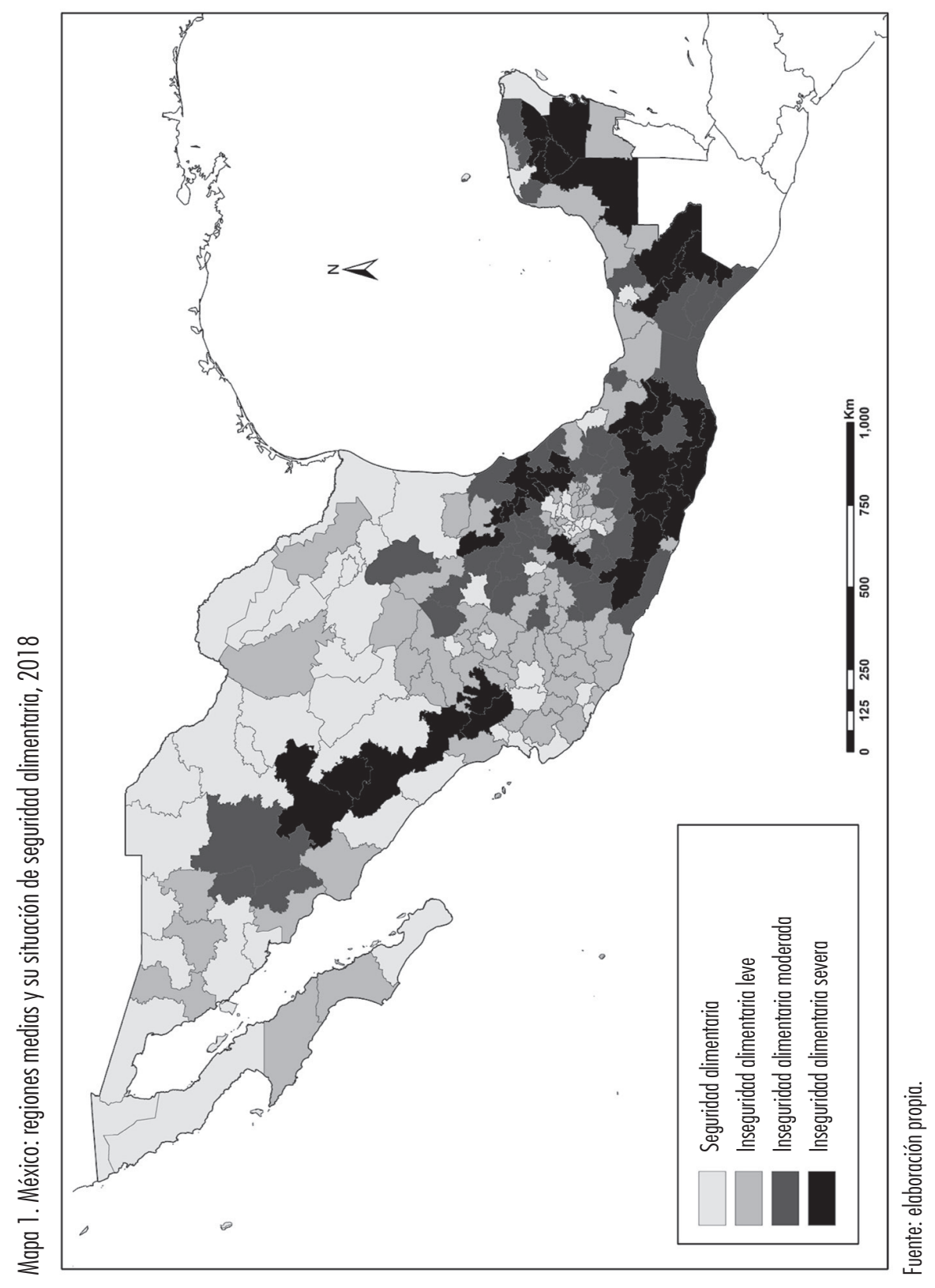


Asimismo, los programas de atención social instaurados desde los años noventa del siglo pasado, que buscaban aliviar temporalmente el problema de la accesibilidad, tuvieron por igual un efecto importante. Sin embargo, al carecer de un componente para activar la producción interna y el autoconsumo entre la población pobre dentro del modelo económico seguido, el cual supere las condiciones coyunturales y ubique la solución de problemas estructurales, no evitaron que la inseguridad alimentaria se incrementara de una región a otra.

Prueba de ello es que el estado mexicano de Oaxaca no registró mejoría en todo el periodo, y únicamente tres de sus regiones medias alcanzaron el nivel de inseguridad alimentaria moderada, mientras que seis de ellas nunca rebasaron el rango de inseguridad alimentaria severa; es el mismo caso de Chiapas con cuatro y cinco en ambos casos, o Guerrero con dos y cuatro del total, si bien una de ellas logró ubicarse en inseguridad alimentaria leve.

Una situación similar correspondería al estado de Yucatán con tres, cuatro y una respectivamente, de Hidalgo, Tabasco, Durango y Campeche, aunque este último presenta una mayor polarización, en la medida que, de sus tres regiones medias, dos de ellas se ubican en inseguridad alimentaria leve y una en inseguridad alimentaria severa. El estado de Guanajuato, sin alcanzar condiciones óptimas, de sus seis regiones, tres se ubican en inseguridad alimentaria leve, tres en inseguridad alimentaria moderada y ninguna en inseguridad alimentaria severa; un nivel similar se manifiesta en las regiones medias de Tlaxcala.

Un hecho preocupante es que la connotación del deterioro de las condiciones alimentarias en su vertiente territorial refleja también cómo afecta cada vez más a las capas medias de la población, pierden su ubicación en el rango de seguridad alimentaria, para insertarse en el de inseguridad alimentaria leve o inseguridad alimentaria moderada. Este deterioro inhibe las posibilidades presentes y futuras para alcanzar mejores niveles de desarrollo en un ambiente económico competitivo, dado que disminuye con la calidad de su alimentación.

Una constante en los resultados de estudios precedentes y que se repite en este, es que la mayor parte de las regiones medias ubicadas en el rango de seguridad alimentaria se localizan al norte de México, algunos al centro, o bien en entidades que no corresponden a esta categoría como conjuntos, pero integran zonas específicas de alto desarrollo turístico o industrial.

Por ejemplo, en Baja California y Baja California Sur, las regiones que mantuvieron esa condición óptima en el 2000 fueron: Tijuana-Tecate, Ensenada, Loreto Comundú y la Paz; en cambio para 2015, sólo Tijuana-Tecate y la Paz la conservaron. 
Una situación parecida se observó en el caso de Sonora, ya que en el 2000 registró con el rango de seguridad alimentaria a regiones como Desierto de Sonora, Hermosillo Centro, Guaymas Empalme, Yaqui Mayo, Frontera Centro, Río Sonora, San Miguel, Frontera Norte y Sierra Alta; sin embargo, la tendencia fue hacia el deterioro pues sólo se conservaron Hermosillo Centro, Frontera Centro y Frontera Norte.

Es importante destacar, como constante en la heterogeneidad de los cambios de rango de la seguridad alimentaria hacia una peor condición que, en el caso del Estado de México, de las regiones medias que se integran principalmente con los municipios conurbados a la Ciudad de México y que en el 2000 se ubicaron en el rango más alto como fue el caso de Cuautitlán Izcalli, Naucalpan, Tlalnepantla, Tultitlán, Ecatepec, Nezahualcóyotl y Texcoco, este último perdió ese nivel en 2018, si bien las alcaldías que corresponden a la actual Ciudad de México lo conservaron en todo el periodo.

Resulta también de interés, en el marco de la heterogeneidad señalada, que algunas de las regiones medias ubicadas para el 2000 en entidades federativas consideradas como las más rezagadas como Región XI Apan (Hidalgo), Metropolitana (Yucatán) y Caribe Norte (Quintana Roo), sólo esta última se mantuvo; en cambio apareció en este rango la Región XII Tizayuca (Hidalgo). Estos cambios han generado que casi 1.2 millones de habitantes perdieran su ubicación en el rango de seguridad alimentaria, con lo que se infiere que transitaron hacia inseguridad alimentaria leve o inseguridad alimentaria moderada que llevaría a un paulatino deterioro en la calidad de la alimentación del país.

Lo anterior refuerza la tesis de que los rezagos existentes en la inseguridad alimentaria interna obedecen más bien a un problema estructural del desarrollo económico, que mantiene o tiende a profundizar las desigualdades, las cuales pueden deslocalizarse cíclicamente en términos regionales, pero deja intacto el problema en la medida que reproduce la pobreza y no resuelve otros factores de rezago en la producción y estabilidad agroalimentaria que genera la dependencia también estructural del sector.

Por ello, de las 37 regiones medias registradas en inseguridad alimentaria severa para el 2000, disminuyeron a 31 en 2015, pero repuntaron a 57 en 2018. De estas últimas, Durango registró una (La Quebrada), San Luis Potosí dos (Huasteca Centro y Huasteca Sur), Nayarit una (Sierra Nayarit), Jalisco una (Norte Jalisco) y Estado de México tres (Valle de Bravo, Tejupilco y Atlacomulco); el resto se localizan en las entidades más pobres, mismas que se han mantenido a lo largo del tiempo. Para 2018, sólo salieron del rango analizado dos del Estado de México (Atlacomulco y Tejupilco), una de Querétaro 
(Tejupilco), tres de Veracruz (Huasteca Alta, Huasteca Baja y Los Tuxtlas) y una de Hidalgo (Zimapán), el resto mantuvieron la misma condición.

Aunque la unidad de medición en el presente análisis es la región media, no se pueden considerar esos resultados regionales al margen de la población que se localiza en ellas. La proporción porcentual entre regiones medias y el número de habitantes para los distintos rangos de seguridad alimentaria puede ser diferente en magnitud, aunque presente la misma dinámica de comportamiento en el tiempo. Una evidencia es que el número absoluto de población en una mejor o peor condición casi no muestra cambios durante el periodo analizado, pero se manifiesta un incremento proporcional con la que se ubica en condiciones peores de manera constante en relación con la población total. Reiterando: el problema de la seguridad alimentaria permanece enraizado como problema estructural del desarrollo en México.

Si se analizan esa regiones de acuerdo con sus niveles de concentración de población, se obtiene que el estado de inseguridad alimentaria en zonas rurales críticas se dispersa hacia grandes concentraciones de población, de tal manera que se infiere una disminución en los niveles de seguridad alimentaria de éstas, aunque no impacten claramente en sus rangos debido a que las personas que trasladan su inseguridad alimentaria territorialmente, se mantiene, aunque dispersa dentro de la heterogeneidad urbana de las principales zonas metropolitanas.

Al ubicar las regiones medias - de acuerdo con su tamaño de población-, se observa que entre quienes alcanzan el rango de seguridad alimentaria, si bien se incrementó en 9.1 millones de personas en términos absolutos, la proporción se contrajo al pasar de 50.1 a 46.7\%, entre el inicio y final del periodo 2000-2018, lo que expresa que más de la mitad de los mexicanos presentan algún grado de inseguridad alimentaria (véase cuadro 7).

La población que antes experimentaba una condición de seguridad alimentaria se trasladó hacia los estratos de inseguridad alimentaria leve e inseguridad alimentaria moderada, debido a que el rango de inseguridad alimentaria severa no tuvo cambios significativos durante el periodo. Este fenómeno obedece fundamentalmente al deterioro en las condiciones de vida de las personas, a la parálisis en la producción de alimentos, al éxodo campesino y al detrimento en la situación nutrimental y de salud.

La población ubicada en inseguridad alimentaria leve aumentó 12.5 millones, lo que significó en términos porcentuales un incremento de 21.5 a 27.1\%, respecto a la población total. En el caso de la inseguridad alimentaria moderada, la población ubicada en este estrato registró una dinámica distinta, aunque aumentó en su situación absoluta, al pasar de 16.8 a 18 millones de personas, en términos relativos disminuyó de 17.3 a $14.6 \%$ en el mismo periodo. 


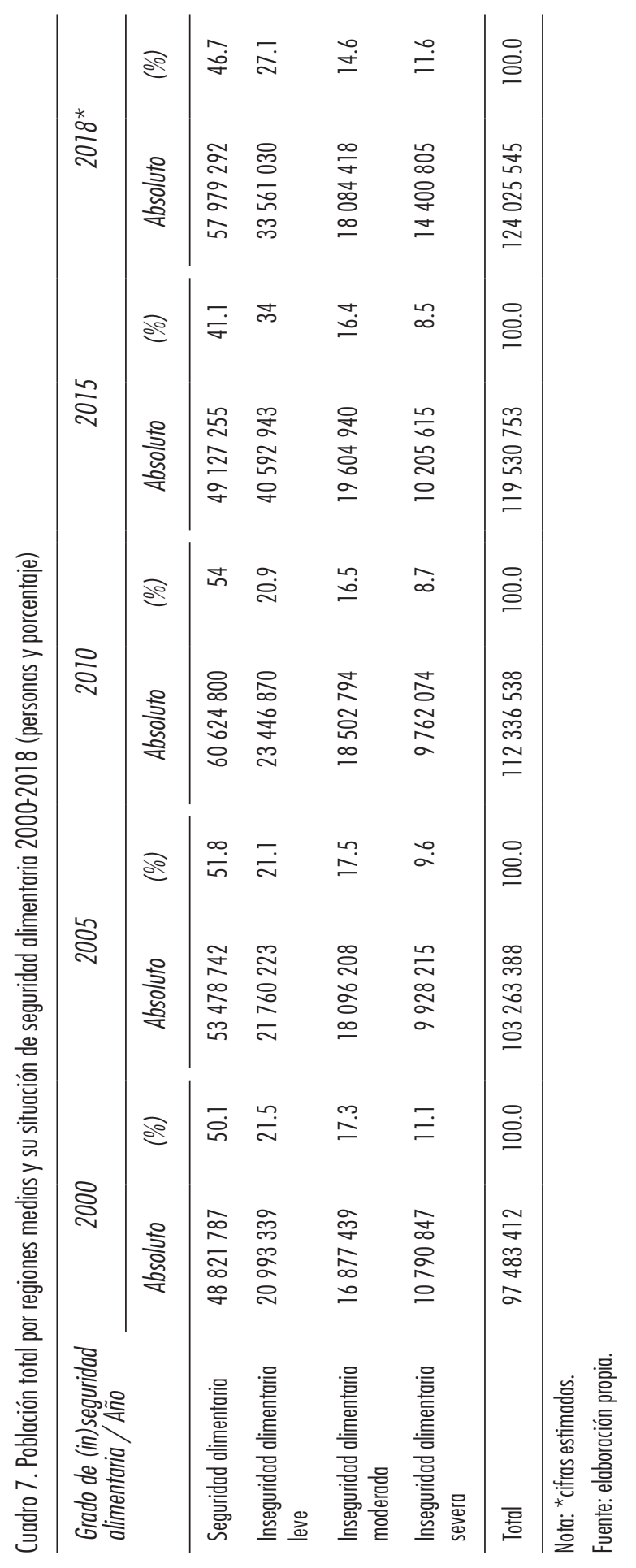


Finalmente, la población situada en inseguridad alimentaria severa empeoró su situación. Al inicio del periodo, 10.7 millones de personas padecieron esta condición, lo cual se redujo a 9.7 millones en 2010; sin embargo, repuntaron a 10.2 millones en 2015 y alcanzó su máximo en 2018 con 14.4 millones. La proporción aumentó marginalmente, en este último caso, del 11.1 a $11.6 \%$. Vale señalar que lo que se incrementó realmente fueron las cantidades de los consumos de manera temporal y no de cobertura de la seguridad alimentaria, debido a que la producción regional de alimentos no mejoró y menos con ello la complementariedad de suministros por autoabasto entre la población rural. Visto por el lado del número de regiones o del tamaño de la población, más de la mitad de los mexicanos enfrenta en la actualidad algún grado de inseguridad alimentaria.

\section{CONCLUSIONES}

Los saldos en materia alimentaria en el periodo establecido en México han sido la crisis y el estancamiento del sector agropecuario, el rezago de su estructura productiva, el desmantelamiento de la base campesina y el éxodo rural, la pérdida de la autosuficiencia alimentaria y mayor dependencia de las importaciones de alimentos, el saldo deficitario estructural de las cuentas externas agroalimentarias, así como un déficit en la balanza comercial, que han ido acompańados de los bajos niveles de crecimiento de la economía nacional, las caídas del salario y del poder adquisitivo, la contracción en el nivel de empleo, el repunte de la pobreza, principalmente una permanente vulnerabilidad alimentaria que se manifiesta de manera diferenciada en el territorio nacional.

El reto para la seguridad alimentaria en México, desde su acceso, extensivo a la producción agropecuaria, consiste en producir alimentos suficientes a bajo costo, garantizar el abasto y la obtención de los mismos; preservar el medio ambiente mediante esquemas productivos óptimos de aprovechamiento de los recursos para evitar estallidos sociales regionales, mediante la generación de empleo directo en el campo, garantizando niveles de certeza en la posesión de la tierra; diseminación regional del crédito agrícola en la producción de básicos y medidas proteccionistas temporales y diferenciadas en los precios que frenen el embate de la apertura comercial sobre esquemas no competitivos como los actuales.

La seguridad alimentaria debe tener como base el crecimiento sostenido de la economía interna por medio de mecanismo eficientes de distribución del 
ingreso, donde la recuperación del poder adquisitivo, aunado a la generación de empleo temporal y estacional en el campo, que puede no estar relacionado sólo con las actividades agrícolas, deben ayudar a recuperar los niveles de consumo y generar un dinamismo creciente de las cadenas productivas vinculadas con la producción de alimentos.

\section{BIBLIOGRAFÍA}

Ávila, A., Juárez-Martínez, L., Del Monte-Vega, M., Ávila Arcos, MA., Galindo-Gómez, C. y Ambrocio-Hernández, R. (2016), Estado de nutrición en población escolar mexicana que cursa el nivel de primaria, México, Instituto Nacional de Ciencias Médicas y Nutrición "Salvador Zubirán”.

Consejo Nacional de Evaluación de la Política de Desarrollo Social (Coneval) (2017), Medición de la pobreza en México y en las entidades federativas 2016. Resumen ejecutivo, México, Coneval.

Hair, J., Black, W., Babin, B. y Anderson, R. (2014), Multivariate Data Analysis, Estados Unidos, Pearson.

Instituto Nacional de Estadística y Geografía (INEgI) (2000), XII Censo de Población y Vivienda 2000. Marco conceptual, México, INEGI.

(2005), II Conteo de Población y Vivienda 2005. Características metodológicas y conceptuales, México, INEGI.

(2010a), Marco conceptual del Censo de Población y Vivienda 2010, México, INEGI.

(2010b), Nota técnica. Estratificación multivariada (Sistema para la Consulta de Información Censal 2010), México, Inegi. Recuperado de <http://gaia.inegi.org.mx/scince2/documentos/scince/fichaTecnica.pdf> (2015), Encuesta Intercensal 2015, México, INEGI.

Morón, C. y Schejtman, A. (1997), "Situación de la seguridad alimentaria en América Latina”, en C. Morón, I. Zacarías y S. de Pablo (eds.), Producción y manejo de datos de composición química de alimentos en nutrición, Chile, FAO.

Organización de las Naciones Unidas para la Alimentación y la Agricultura (FAO) (2009), Declaración de la Cumbre Mundial sobre la Seguridad Alimentaria, Roma, FAO.

(2016), Pérdidas y desperdicios de alimentos en América Latina y el Caribe. Boletín electrónico 3. Recuperado de <http://www.fao.org/3/a-i5504s. pdf> 
(FAO) (2018), Alianzas alimentarias contra el hambre y la malnutrición. Primera Cumbre Parlamentaria Mundial, Madrid, FAO.

Puyana, A. y Romero, J. (2009), "El sector agropecuario mexicano bajo el Tratado de Libre Comercio de América del Norte. La pobreza y la desigualad se intensifican, crece la migración", en C. Barba Solano (comp.), Retos para la integración social de los pobres en América Latina, Buenos Aires, Consejo Latinoamericano de Ciencias Sociales.

Rouzaud, O. (2008), "El concepto 'seguridad alimentaria”, Revista Universidad de Sonora, núm. 22, México, Universidad de Sonora.

Sánchez, A. (2018), El Producto Interno Bruto de los municipios de México, 1970-2015. Estimaciones para el análisis territorial, México, UNAM-IIEc.

Sistema Nacional para el Desarrollo Integral de la Familia (DIF)-Secretaría de Educación Pública (seP)-Instituto Nacional de Ciencias Médicas y Nutrición "Salvador Zubirán" (InCMnsz) (1994), Primer Censo Nacional de Talla 1993, México, DIf-SEP-INCMNSZ.

(1997), Segundo Censo Nacional de Talla 1994, México, DIF-SEPINCMNSZ.

(2004), Tercer Censo Nacional de Talla 1999, México, DIF-SEPINCMNSZ.

(2006), Cuarto Censo Nacional de Talla 2004, México, DIF-SEP-SSAINCMNSZ.

The Economist Intelligence Unit y DuPont (UIE y DuPont) (2017), Global food security index 2017: measuring food security and the impact of resource risks, Londres, UIE y DuPont.

Torres, F. (2017), "La seguridad alimentaria en la estructura del desarrollo económico de México", en F. Torres Torres (coord.), Implicaciones regionales de la seguridad alimentaria en la estructura del desarrollo económico de México, México, UnAm-IIEc.

Torres, F. y Rojas, A. (2018), "El suelo agrícola en México: retrospección y prospectiva para la seguridad alimentaria”, Realidad, datos y espacio. Revista Internacional de Estadistica y Geografía, vol. 9, núm. 3, México, INEGI. 
